\title{
Anticancer properties of colicin E7 against colon cancer
}

\author{
Morovat Taherikalani ${ }^{1}$, Sobhan Ghafourian ${ }^{2}$ \\ ${ }^{1}$ Razi Herbal Medicine, Lorestan University of Medical Sciences, Khorramabad, Iran \\ ${ }^{2}$ Department of Microbiology, School of Medicine, Ilam University of Medical Sciences, Ilam, Iran
}

Gastroenterology Rev 2021; 16 (4): 364-368

DOI: https://doi.org/10.5114/pg.2021.109622

Key words: colicin E7, colon cancer, anticancer.

Address for correspondence: Sobhan Ghafourian, Department of Microbiology, School of Medicine, Ilam University of Medical Sciences, Ilam, Iran, e-mail: sobhan.ghafurian@gmail.com

\begin{abstract}
Introduction: Cancer is a major public health problem in the modern world. Every year, new cases of cancer are diagnosed around the world. Cancer cells are altered cells that have escaped the mechanisms that regulate natural growth. Bacteriocins are cationic peptides synthesized by ribosomes that are secreted by almost all groups of bacteria. Some bacteriocins have shown selective toxicity to cancer cells compared to normal cells. This makes them other candidates for research and clinical trials.

Aim: Due to the high prevalence of colon cancer and its therapeutic problems, this study was performed on colicin E7 to evaluate its anti-colon cancer properties.

Material and methods: For this reason, colE7 was cloned in pet32c vector and purified protein was affected on HT-29 cells to evaluate the expression of $\mathrm{p} 53$ and bcl2.

Results: Our in silco analysis demonstrated that colicin E7 has $87.23 \%$ confidence as anticancer peptide by ACPred-FL program. First, a PCR reaction was performed using specific primers of the colicin E7 gene, which formed the 1728 bp fragment that belongs to this gene.

Conclusions: Colicin E7 decreased the expression of bcl2 and increased P53. The results of this study showed the general effect of colicin E7 on cancer cells in vitro, which can be evaluated in the future with further experiments.
\end{abstract}

\section{Introduction}

Cancer is a major public health problem in the modern world. Every year, new cases of cancer are diagnosed around the world [1]. Cancer cells are altered cells that have escaped the mechanisms that regulate natural growth. Under normal circumstances, the balance between cell regeneration and cell death is maintained and new cell production is adjusted so that the number of specific cell types remains constant [2]. But due to environmental or inherited genetic mutations, the mechanisms that control the normal growth of the cell are stopped, causing the cell clones to expand significantly, leading to the production of a tumour or neoplasm. The current strategies for treating cancer include chemotherapy, surgery, and radiation therapy. Chemotherapy is the main treatment of choice. But chemotherapy drugs are often associated with drug-induced damage to healthy cells and tissues, and do not specifically target cancer cells. Also, cancer cells often turn into chemotherapy-resistant cells due to various factors, such as increased expression of detoxifying enzymes and drug transporters, and increased ability to repair DNA defects in cell organizations that involve apoptosis. Despite advances in treatment and diagnosis, including improvements in surgery, radiation therapy, and chemotherapy, these treatments may lead to severe side effects or increased resistance and can have a long-term negative impact on human health $[3,4]$. Therefore, there is a need to develop other treatment options to add to the available treatments, and there is an urgent need for specific and targeted treatment of cancer cells that can alone treat cancer or be used as an adjuvant to reduce therapeutic doses of common anticancer drugs [5]. Some experimental studies have reported the therapeutic potential of bacteriocin against different types of cancer cells [6]. Bacteriocins are cationic peptides 
synthesized by ribosomes that are secreted by almost all groups of bacteria. Some bacteriocins have shown selective toxicity to cancer cells compared to normal cells [6]. This makes them candidates for research and clinical trials.

\section{Aim}

Due to the high prevalence of colon cancer and its therapeutic problems, this study was performed on colicin E7 to evaluate its anti-colon cancer properties.

\section{Material and methods \\ In silico analysis}

To determine the possibility of colicin E7 as an anticancer drug, it was evaluated in the ACPred-FL [7] and AntiCP 2.0 database [8].

\section{PCR for identification of colicin E7}

The PCR reaction was performed using specific primers for the presence of the colicin E7 gene. Then, the PCR product (colE7 gene) was electrophoresis on a $1.1 \%$ agarose gel at a voltage of $80 \mathrm{~V}$ for $70 \mathrm{~min}$. Bacterial DNA purification was performed using the DNA purification kit (Korea, GeneAll) according to the instructions.

\section{Plasmid vector}

Pet32c expression vector was obtained from Merck, Germany. The pet32c vector was used to make a recombinant plasmid containing the colicin E7 gene. Before transferring the gene into the ligation vector, the pulsed vectors were first cut with the appropriate restriction enzymes.

In general, $1 \mu \mathrm{l}$ of restricted enzyme BamHI FastDigest and HindIII FastDigest per $1 \mu \mathrm{g}$ of plasmid DNA were used and incubated for 15 to $20 \mathrm{~min}$ at $37^{\circ} \mathrm{C}$. They were inactivated at $80^{\circ} \mathrm{C}$ for $10 \mathrm{~min}$. Ligation processes were done in the presence of vector and DNA insertion in a $3: 1$ molar ratio, T4 DNA Ligase Buffer, DNA ligase, and $\mathrm{H}_{2} \mathrm{O}$. The total volume was $20 \mu \mathrm{l}$. The mixture was incubated at $22^{\circ} \mathrm{C}$ for $1 \mathrm{~h}$, and then the enzyme was inactivated by heating at $65^{\circ} \mathrm{C}$ for $10 \mathrm{~min}$. Then, according to the instructions of Sambrook and Russell, component cells of E. coli were prepared. After that, the transformation was done as follows.

The competent $E$. coli bl21 bacterial cells were placed on ice until they melted. Then, $8 \mu$ of the ligation mixture was added to the micro tube containing $100 \mu \mathrm{l}$ of the competent cell and incubated on ice for $30 \mathrm{~min}$. Then, it was heated at $42^{\circ} \mathrm{C}$ for $50 \mathrm{~s}$ in a hot water bath. Then, $250 \mu \mathrm{l}$ of SOS medium (yeast extract 5.0\%, tryptone $2 \%, 5.2 \mathrm{mM}$ glucose, $10 \mathrm{mM} \mathrm{NaCl}$ ) was added to the microtube and incubated at $37^{\circ} \mathrm{C}$ for $1 \mathrm{~h}$ in a shaker incubator. Finally, $250 \mu \mathrm{l}$ of the transformation reaction was transferred to a $0.1 \mathrm{mM}$ Isopropyl $\beta$-D-1-plate, $100 \mathrm{~g} / \mathrm{ml}$ ampicillin containing LB medium containing IPTG (thiogalactopyranoside) and $40 \mathrm{ml} / \mu \mathrm{g}$ Gal-X 40, and incubated overnight at $37^{\circ} \mathrm{C}$.

\section{Identification of recombinant $E$. coli}

Recombinant colonies by white-blue colony on agar medium containing IPTG (1.0 mM) ampicillin $100 \mu \mathrm{l} / \mathrm{ml}$ and Gal-X $40 \mu \mathrm{g} / \mathrm{ml}$ were detected. Also, to confirm the cloning, plasmid extraction by Miniprep was performed. Then, positive recombinant colonies obtained from the previous screening under the influence of single and double restriction enzymes Hind III FastDigest and Bam$\mathrm{HI}$ and the presence and size of the gene inserted in them was evaluated. The digested plasmid was examined by agarose gel electrophoresis.

\section{Protein purification}

Colicin E7 was purified using a Thermo Scientific HisPur Ni-NTA Spin Purification Kit. Also, the concentration and protein identification was performed by cell biolabsAKR-130 his-tag protein ELISA kit.

\section{Effect of colicin E7 on HT29 cell line}

Initially, cells in the logarithmic growth phase were trypsinised, implanted in 96-well plates, and incubated in a G: incubator. After $24 \mathrm{~h}$, different concentrations of protein were added to the cell, and after the required time they were examined by MTT method. It should be noted that a concentration of $5 \mu \mathrm{M}$ Oxaliplatin was used to treat HT-29 cells as a positive control.

\section{qPCR for identification of the effect of colicin E7 on HT-29}

Firstly, RNA was extracted using an RNA extraction kit (GENEALL, South Korea) and subjected to cDNA synthesis using a SCRIPT cDNA Synthesis kit (Germany). Secondly, the specific primers for the bcl 2 and $P 53$ genes were designed using GenScript software and synthesized. The ability of the primers for each specific gene to amplify the appropriate amplicon length was evaluated using $4 \mu \mathrm{l}$ of cDNA in a total volume of $20 \mu \mathrm{l}$ per reaction in a Mastercycler ${ }^{\circledast}$ RealPlex 2 (Eppendorf, Germany) with SYBR Green PCR Master Mix. The thermocycling conditions consisted of an initial denaturation for $15 \mathrm{~min}$ at $95^{\circ} \mathrm{C}$, followed by 40 cycles at $95^{\circ} \mathrm{C}$ for $15 \mathrm{~s}, 60^{\circ} \mathrm{C}$ for $40 \mathrm{~s}$, and $68^{\circ} \mathrm{C}$ for $20 \mathrm{~s}$. The RT-qPCR results were then analysed quantitatively to estimate the levels of $b c / 2$ and P53 mRNA. 


\section{Results}

The potential of colicin $\mathrm{E} 7$ as an anticancer peptide

Our analysis demonstrated that colicin E7 has $87.23 \%$ confidence for anticancer peptide by ACPred-FL program and it was also confirmed as a potent anticancer peptide by AntiCP 2.0 (Figure 1). Both databases showed that colicin E7 has a potential to be an anticancer peptide.

\section{Detection of colicin E7 in E. coli}

As described in the methods, the colicin primer was designed based on the colicin E7 gene sequence. The best result was found at an annealing temperature of $59.6^{\circ} \mathrm{C}$. Colicin gene amplification was performed by PCR method and in order to confirm the amplification of the DNA, and a fragment of the desired PCR products was electrophoresis on $1 \%$ agarose gel, and then colicin E7 gene was purified from the agarose gel. A PCR reaction was performed using specific primers of the colicin E7 gene; it formed the $1728 \mathrm{bp}$ fragment that belongs to this gene (Figure 2).
The purified colicin E7 gene was then inserted into the pet32c vector. In the next step, the ligation product was transferred to $E$. coli bl21, and then it was grown in LB agar medium containing $100 \mu \mathrm{g} / \mathrm{ml}$ ampicillin, $0.1 \mathrm{mmol} / / \mathrm{IPTG}$, and $40 \mu \mathrm{g} / \mathrm{ml} \mathrm{X-Gal} \mathrm{at} 37^{\circ} \mathrm{C}$ for $24 \mathrm{~h}$.

After overnight incubation at $37^{\circ} \mathrm{C}$, positive recombinant colonies were selected on agar medium based on the blue/white screening method. White colonies were collected and cultured on new LB agar plates containing $100 \mu \mathrm{g} / \mathrm{ml}$ ampicillin, after which plasmid was extracted and enzymatic digestion was performed to confirm the presence of colicin E7 gene.

DNA sequencing was also performed to investigate the presence as well as the placement of the colicin E7 gene ligation in the recombinant vector. The results of colicin E7 gene blasting using the Chromas program showed that the homologation was 100\%. After confirmation, recombinant pet32c-colicinE7 vectors were stored at $20^{\circ} \mathrm{C}$ until use. Then, colicin E7 was purified and the effect of it was evaluated against HT-29 cells. The results are shown in Figures 3 and 4.

A

\section{ACPred-FL}

A sequence-based predictor for identifying anti-cancer peptides from proteins sequences

Result

Results

$\begin{array}{llll}\text { Title } & \text { Sequence } & \text { Anti-cancer or not } & \text { Confidence } \\ >110 & \text { pktrtqdivsgkrtsfelhhekpisqnggvydmdnisvvtpkrhidihrgk } & \text { anti-cancer } & 87.23 \%\end{array}$

B

User can click on the columns in order to check the sorted results

\begin{tabular}{|c|c|c|c|}
\hline $\begin{array}{l}\text { Peptide } \\
\text { ID }\end{array}$ & Peptide Sequence & $\begin{array}{l}\text { Prediction } \\
\text { Score }\end{array}$ & Prediction \\
\hline$>1016$ & ELHHEKPISQ & 0.48 & AntiCP \\
\hline$>1017$ & LHHEKPISQN & 0.52 & AntiCP \\
\hline$>1034$ & NISWTPKRH & 0.51 & AnticP \\
\hline$>1035$ & ISWTPKRHI & 0.76 & AntiCP \\
\hline$>1036$ & SVVTPKRHID & 0.74 & AntiCP \\
\hline$>1037$ & WVTPKRHIDI & 0.69 & AnticP \\
\hline$>1038$ & VTPKRHIDIH & 0.72 & AntiCP \\
\hline$>1039$ & TPKRHIDIHR & 0.70 & AntiCP \\
\hline$>1040$ & PKRHIDIHRG & 0.63 & AnticP \\
\hline$>1041$ & KRHIDIHRGK & 0.63 & AntiCP \\
\hline
\end{tabular}

Figure 1. Anticancer ability of colicin E7 (region name HNHc) by: A - AntiCP 2.0 database protein scan, B - ACPred-FL program 
After exposure of HT-29 cells to colicin, the expression of p53 and bcl-2 were evaluated, which is shown in Figures 3, 4. The results showed a decrease in the expression of blc 2 and an increase of P53 genes. The results of the expression of cancer genes show the effect of colicin E7 on HT-29 cancer cells. The qPCR method was used to evaluate the expression of the gene, which in turn indicates the expression of the protein.

\section{Discussion}

Over the past half century, cancer has become a serious and threatening human health problem. According to new data released by the World Health Organization (WHO), 2.8 million people have died from the disease and 14.1 million new cases of cancer worldwide have been reported [9]. Worldwide, colon cancer is the third most common type of cancer, accounting for $10 \%$ of all cancers. In 2012, there were 1.4 million new cases of the disease, as well as 694,000 deaths. The disease is more common in developed countries, and $65 \%$ of cases are found in these countries [10]. Some research shows that bacteriocins have anti-cancer activity against tumour cells. Research on colicins and their cytotoxic effects on human tumour cells began about 30 years ago, when the first reported colicin was colicin E3, which had significant cytotoxic effects on human HeLa cells [11].

In the present study, after exposure of HT-29 cells to colicin E7, expression of p53 and bcl-2 were evaluated, and the results showed a decrease in the expression of $b c l 2$ and an increase of $P 53$ genes. The results of the expression of cancer genes showed the effect of bacteriocin colicin on cancer cells HT-29. Oxaliplatin was also used for control. The expression of bcl-2 gene decreased in HT-29 cells, in the presence of colicin E7,

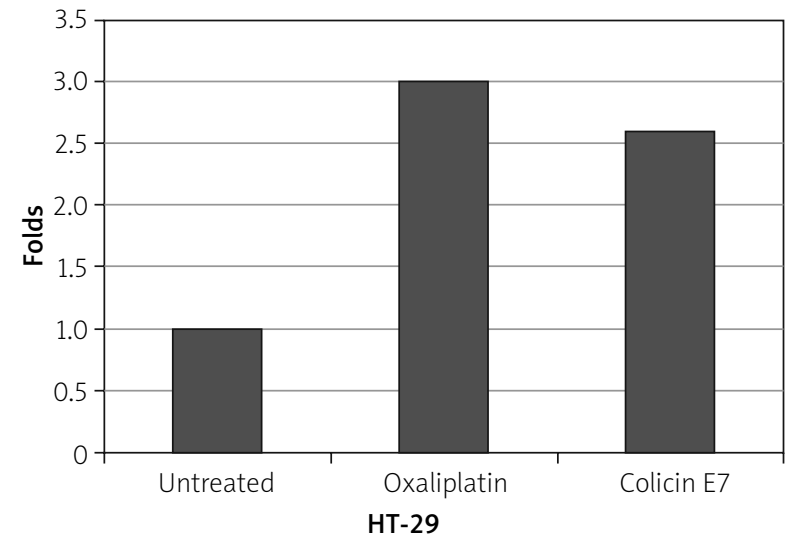

Figure 3. Expression of p53 in HT-29 cells. Oxaliplatin was evaluated as a control. In the presence of colicin E7, the expression of p53 gene was increased

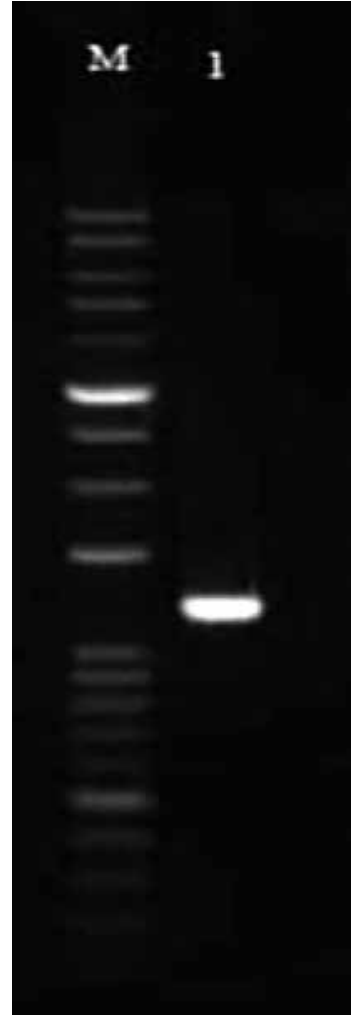

Figure 2. Electrophoresis of colicin gene by PCR $M-$ marker, $1-$ colicin $E 7$ gene $=1730$ bp .

which was near to the effect of oxaliplatin. Also, the expression of p53 in HT-29 cells in the presence of colicin E7 was effective. Although colicins, as a promising group of bacteriocins, appear to have anticancer activity against cancer cells, all aspects of their activity remain unknown [12].

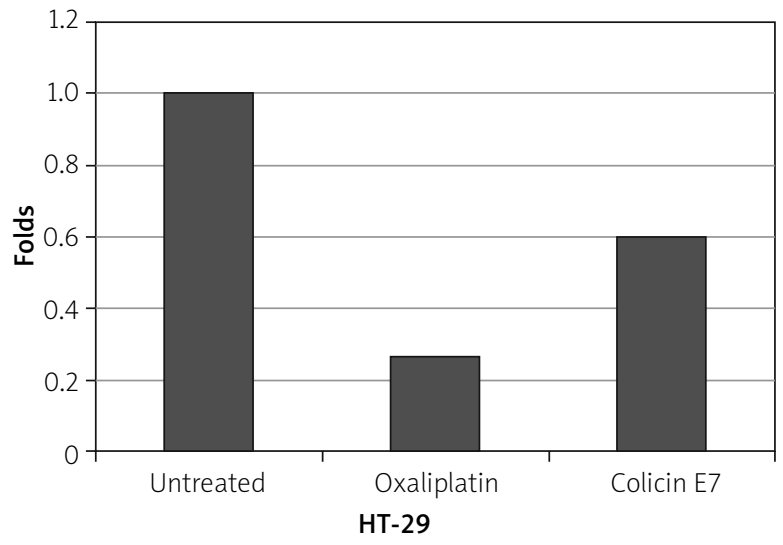

Figure 4. Evaluation of bcl-2 expression in HT29 cells. Oxaliplatin as a control. In the presence of colicin E7, the expression of bcl-2 gene was decreased 


\section{Conclusions}

The results of this study showed the general effect of colicin E7 on cancer cells in vitro, which can be evaluated in the future with further experiments.

\section{Acknowledgments}

Research reported in this publication was supported by the Elite Research Grant committee under award number (943825) from the national institutes for medical research development (NIMAD), Tehran, Iran.

\section{Conflict of interest}

The authors declare no conflict of interest.

\section{References}

1. MaX, Yu H. Global burden of cancer. Yale J Biol Med 2006; 79 85-94.

2. Patel LR, Camacho DF, Shiozawa Y, et al. Mechanisms of cancer cell metastasis to the bone: a multistep process. Future Oncol 2011; 7: 1285-97.

3. Mansoori B, Mohammadi A, Davudian S, et al. The different mechanisms of cancer drug resistance: a brief review. Adv Pharm Bulletin 2017; 7: 339-48.

4. Pan ST, Li ZL, He ZX, et al. Molecular mechanisms for tumour resistance to chemotherapy. Clin Exp Pharmacol Physiol 2016; 43: 723-37.

5. Pucci C, Martinelli C, Ciofani G. Innovative approaches for cancer treatment: current perspectives and new challenges. Ecancermedicalscience 2019; 13: 961.

6. Kaur S, Kaur S. Bacteriocins as potential anticancer agents. Front Pharmacol 2015; 6: 272

7. Wei L, Zhou C, Chen H, et al. ACPred-FL: a sequence-based predictor using effective feature representation to improve the prediction of anti-cancer peptides. Bioinformatics 2018; 34: 4007-16.

8. Agrawal P, Bhagat D, Mahalwal M, et al. AntiCP 2.0: an updated model for predicting anticancer peptides. Brief Bioinformatics 2020; 22: bbaa153.

9. Society AC. Cancer facts \& figures: The Society 2008.

10. World Cancer Report 2014. World Health Organization.

11. Smarda J, Obdrzalek V. The lethal effect of colicin E3 on HeLa cells in tissue cultures. IRCS Med Sci 1977; 5: 524.

12. Chumchalová J, Šmarda J. Human tumor cells are selectively inhibited by colicins. Folia Microbiol 2003; 48: 111-5.

Received: 6.02 .2021

Accepted: 12.03 .2021 